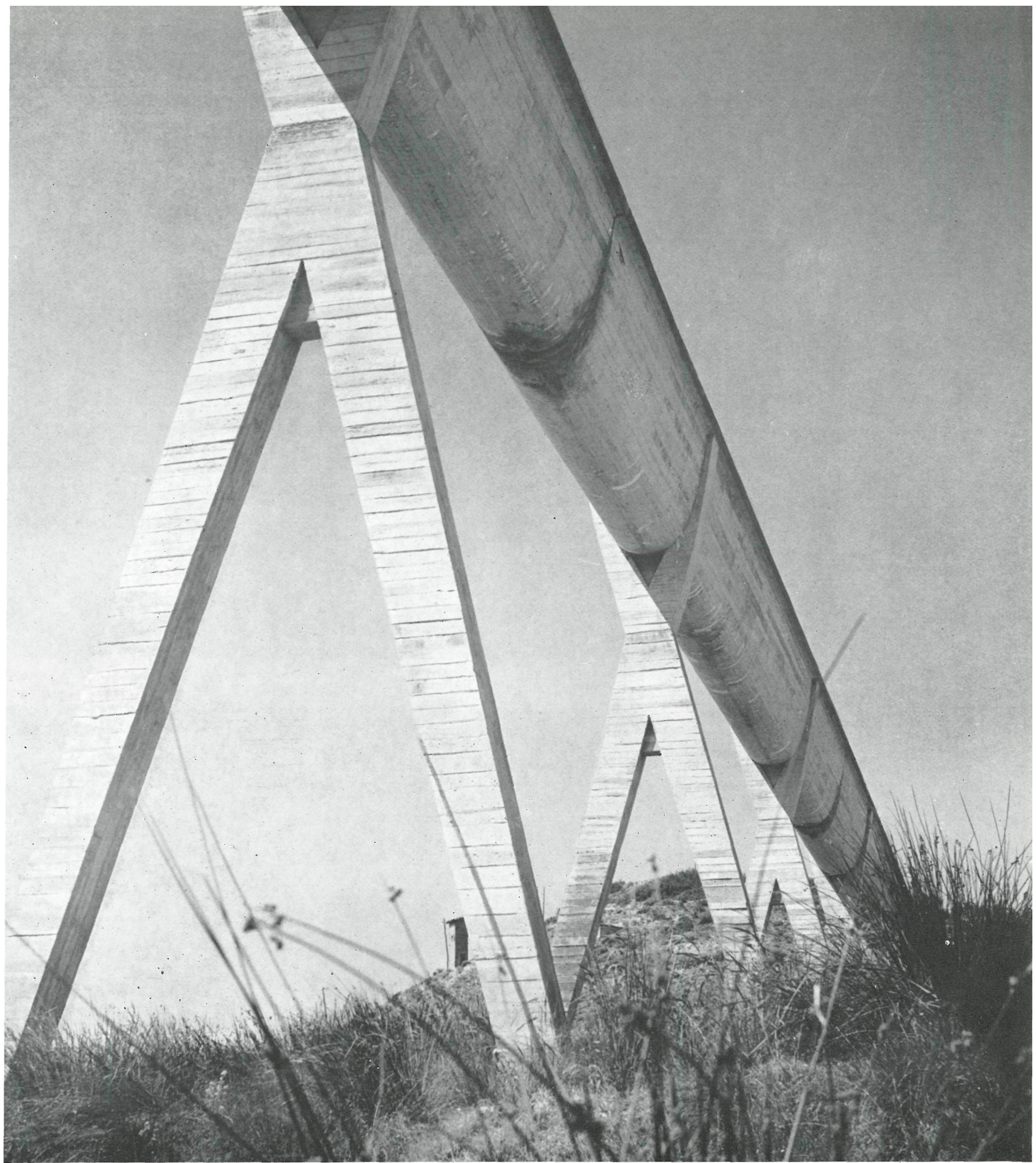

\section{acueducto de alloz}

E TORROJA emplazamiento: Río Salado, Navarra propietario: Fuerzas Eléctricas de Navarra, S. A. año: 1939

constructor: Huarte 
La idea fundamental de este acueducto es la de suprimir la posibilidad de fisuración y de fugas, haciendo que el paramento, en contacto con el agua, esté sometido a compresión en todos los sentidos.

Aunque en las fotografías aparecen fugas de agua, éstas son debidas exclusivamente a la mala calidad y conservación del mastic de las juntas, pues en la pared del acueducto realmente no ha aparecido ninguna fisuración ni filtración de agua.

Para conseguir este resultado, el acueducto está formado de elementos de 40 metros de longitud, apoyados sobre soportes a 20 metros. De este modo, los momentos debidos la flexión de la viga son negativos en toda la longitud; son nulos en los extremos de las ménsulas y en el centro de la viga central, y máximos sobre los apoyos. Basta, por consiguiente, establecer un postensado de los bordes superiores para lograr, en todas las secciones, leyes de compresiones longitudinales, compresiones que abarcan toda la sección y que son mayores abajo, donde la presión del agua es también mayor

Para lograr compresiones en la pared interior según la directriz nor mal a la directriz o longitud del tra mo se disponen barras transversales en los bordes superiores de las U que forman la sección. Estas barras, distanciadas a 4 metros unas de otras, llevan tensores de rosca. Al actuar sobre ellos, se producen momentos flectores transversales de la pared que producen también compresiones crecientes hacia el fondo.

La armadura exterior queda en tracción y resiste no sólo estos momentos transversales, sino también, en los costeros, los esfuerzos cortantes correspondientes a la flexión longitudinal de ménsulas y viga. Estas armaduras transversales se encargan, por último, y especialmente en el fondo, de resistir las tracciones transversales que se producen al quedar este fondo, en cierto modo, colgando de los costeros que funcionan como las almas de la viga longitudinal o de las ménsulas.



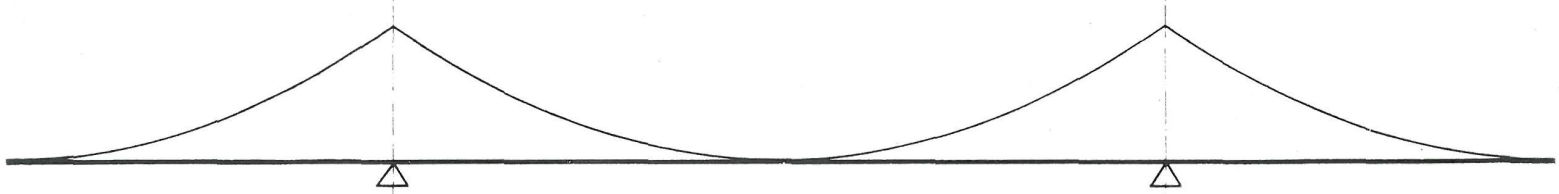

2 cables 4 cables 2 cables tubo

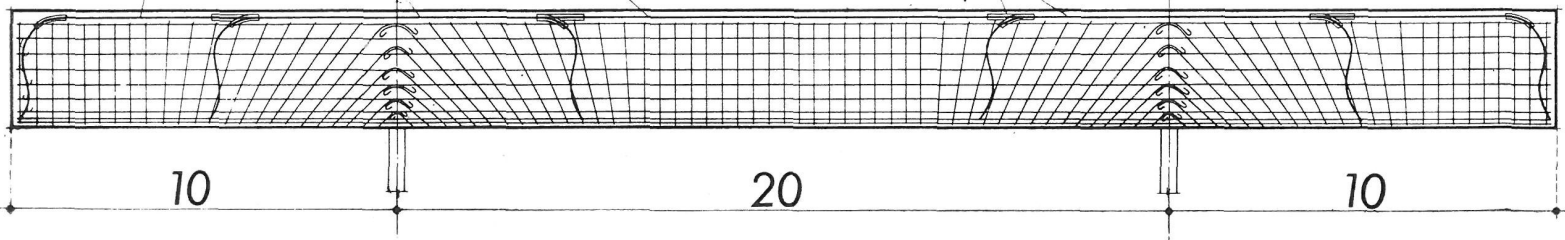

CABLES DE POSTENSADO LONGITUDINAL

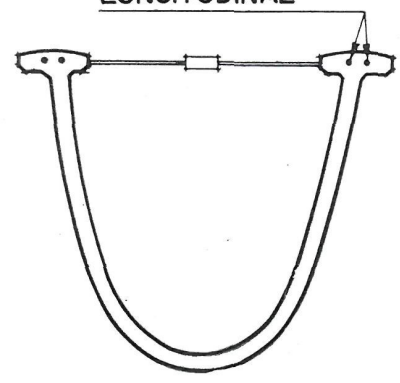

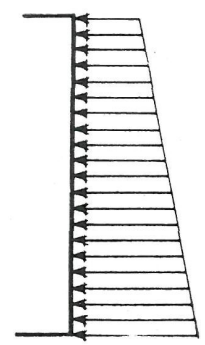

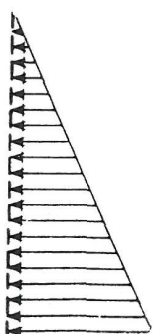

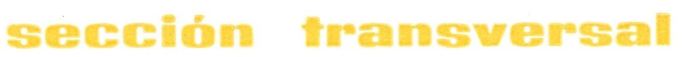

Para lograr fácilmente el postensado longitudinal, se dispusieron dos pares de cables a lo largo de las cajas que forman las cabezas de la U, las cuales, a su vez, sirven de pasarelas o caminos de servicio, y de elementos de rigidez entre los tirantes transversales.

Estos cables quedaban anclados en las paredes desde el momento de hormigonar el conjunto. Como se trata de cables de alambres trenzados, bastaba, para ello, abrir o separar los alambres en las puntas y doblar cada uno de ellos en forma de gancho.

Una vez que el hormigón había adquirido la resistencia prevista, se tesaba cada pareja de cables por el siguiente procedimiento: Los dos cables se sujetaban entre sí en dos puntos mediante llaves; después, en el punto medio entre estas dos llaves, se introducían dos fuerzas iguales y contrarias tendiendo a aumentar la separación de los cables y a acortar la distancia longitudinal entre las llaves. Esta operación se hacía fácilmente con un aparato de tijera entre cuyos brazos actuaba un pequeño gato hidráulico. Un ábaco preparado al efecto permitía determinar la tracción a que estaban sometidos los cables en función de la abertura alcanzada y de la presión del gato. Cuando se había llegado a la tracción prevista, se colocaba un separador que mantenía los cables en esa posición; y si era necesario se repetía la operación en otro punto.

En el caso de que se agotase la separación máxima que permitía la caja de hormigón, sin alcanzar la presión debida en el gato, se repetía la operación en otra zona de la misma pareja de cables.

Los cables, postesados como acaba de indicarse, se cubrían, provisionalmente, con arena para evitar la acción de la intemperie, y, en especial, de la radiación solar. Pasadas algunas semanas, se volvía a colocar el gato para comprobar la tensión; y, en caso necesario, se corregía ésta si, por efecto de la fluencia del acero o la retracción del hormigón, se había perdido algo de tensión.

Después de esta segunda operación, se hormigonaban los cables, se cerraban las juntas entre ménsulas y se daba por terminada la obra. 

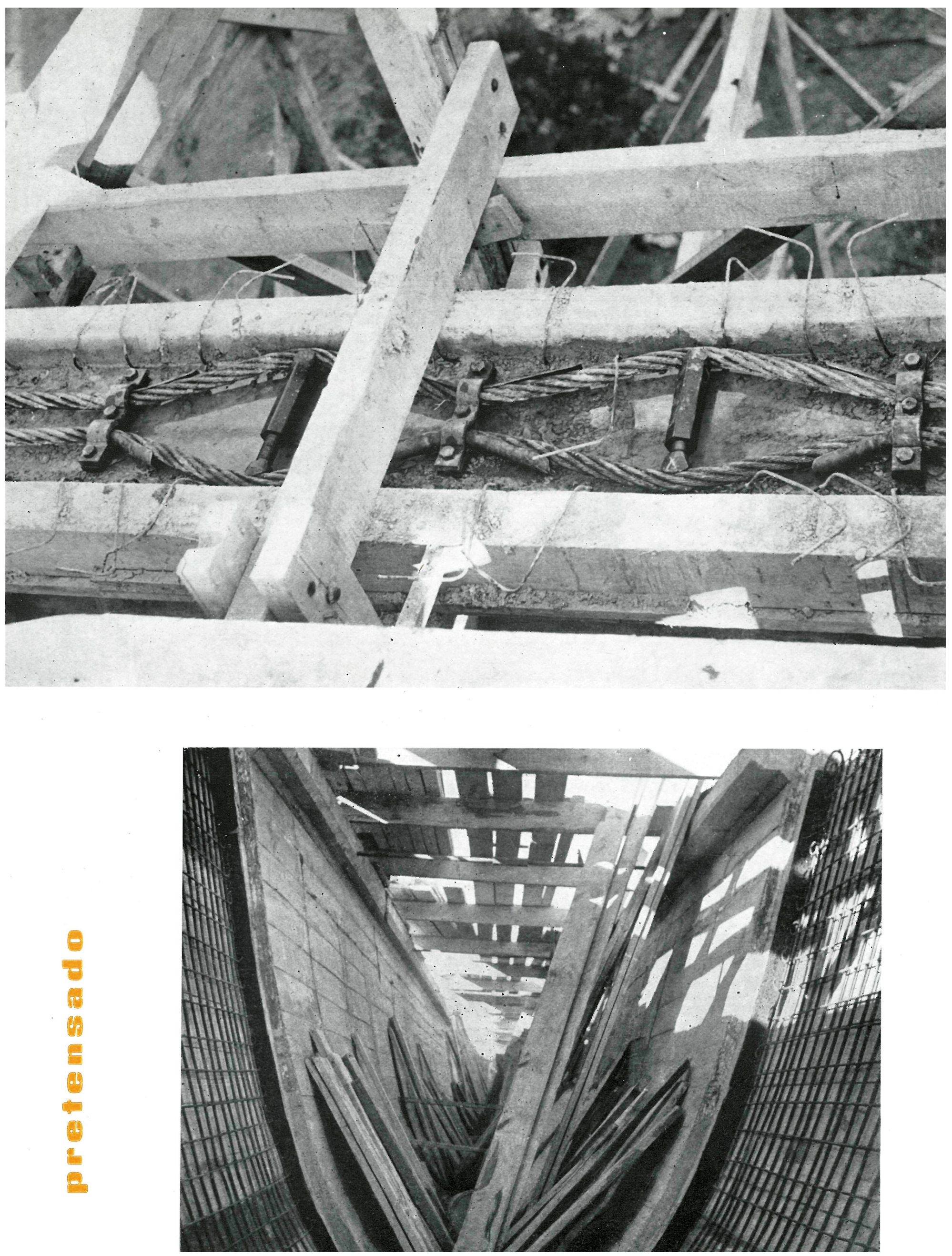


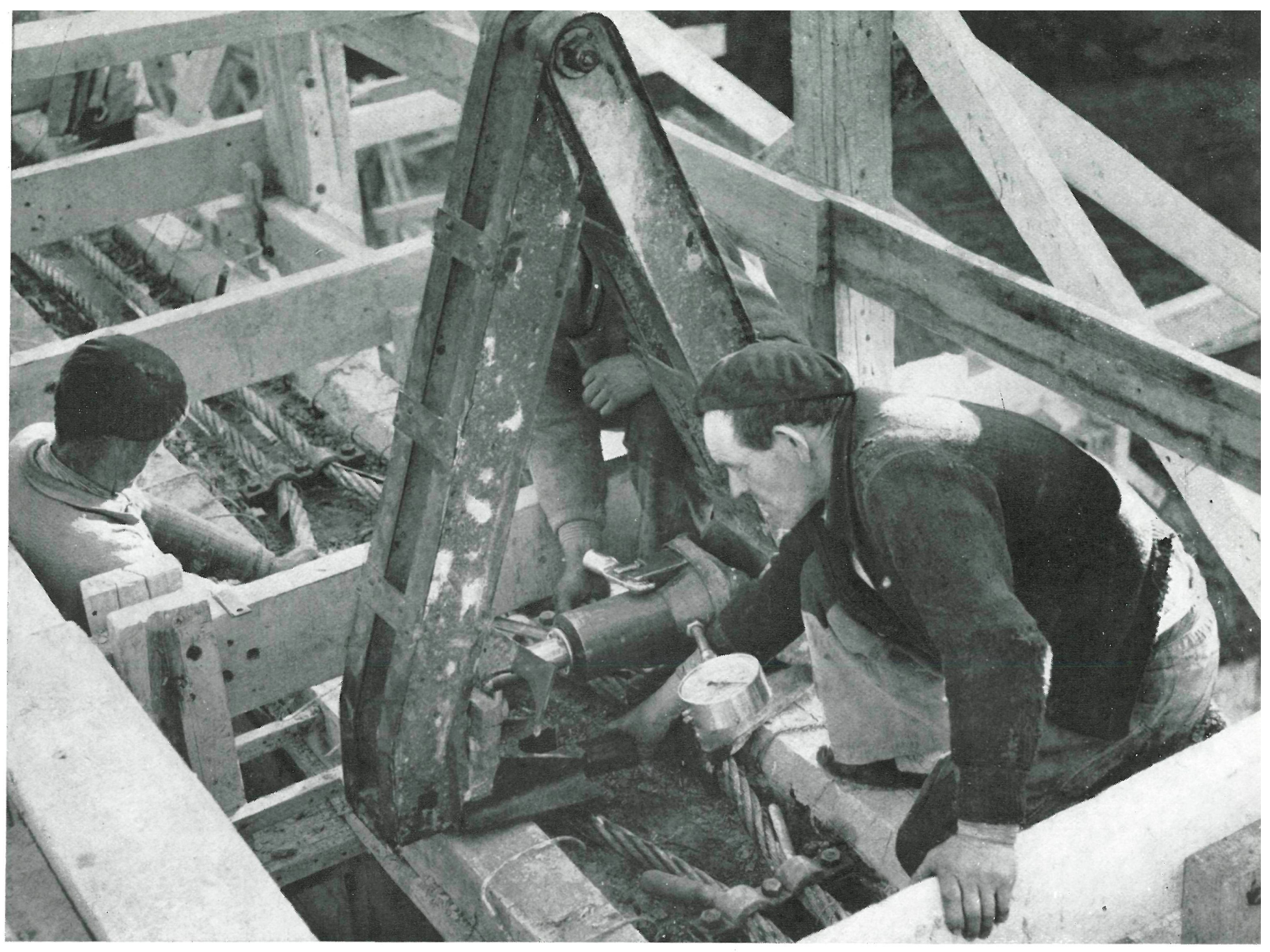

ABRAZADERA

Las juntas llevan unas chapas de plomo embutidas en el hormigón y van recubiertas con mastic bituminoso asfáltico, en el que quedan recibidas unas telas metálicas. Desgraciadamente, el mastic no era de la calidad necesaria y fue preciso sustituirlo, en alguna de las juntas, para evitar fugas; pero esta operación no presenta ninguna dificultad y, si no se ha hecho, es porque las fugas no tienen importancia.

Los soportes están formados por dos patas inclinadas que dan un cierto carácter al conjunto, asegurando perfectamente su estabilidad.

Los soportes se prolongan en forma de $\mathrm{U}$ alrededor de la sección, formando un arco de refuerzo y de sustentación de la viga con sus ménsulas. Como para lograr la compresión transversal de la pared interior se requería que los tensores cerrasen ligeramente la U en toda la sección, se dejaron cortes de hormigonado en la zona exterior de los nervios de refuerzo, sobre los soportes, para que éstos pudiesen también seguir esta ligera deformación sin demasiada rigidez.

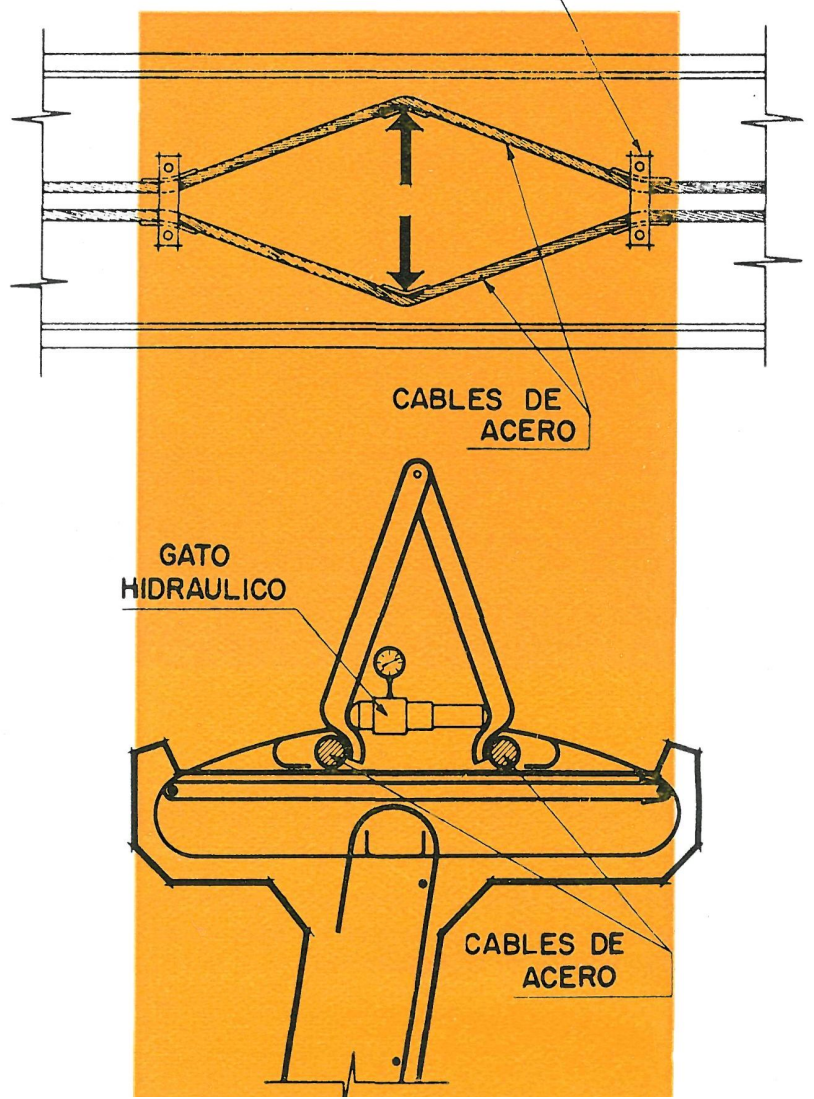




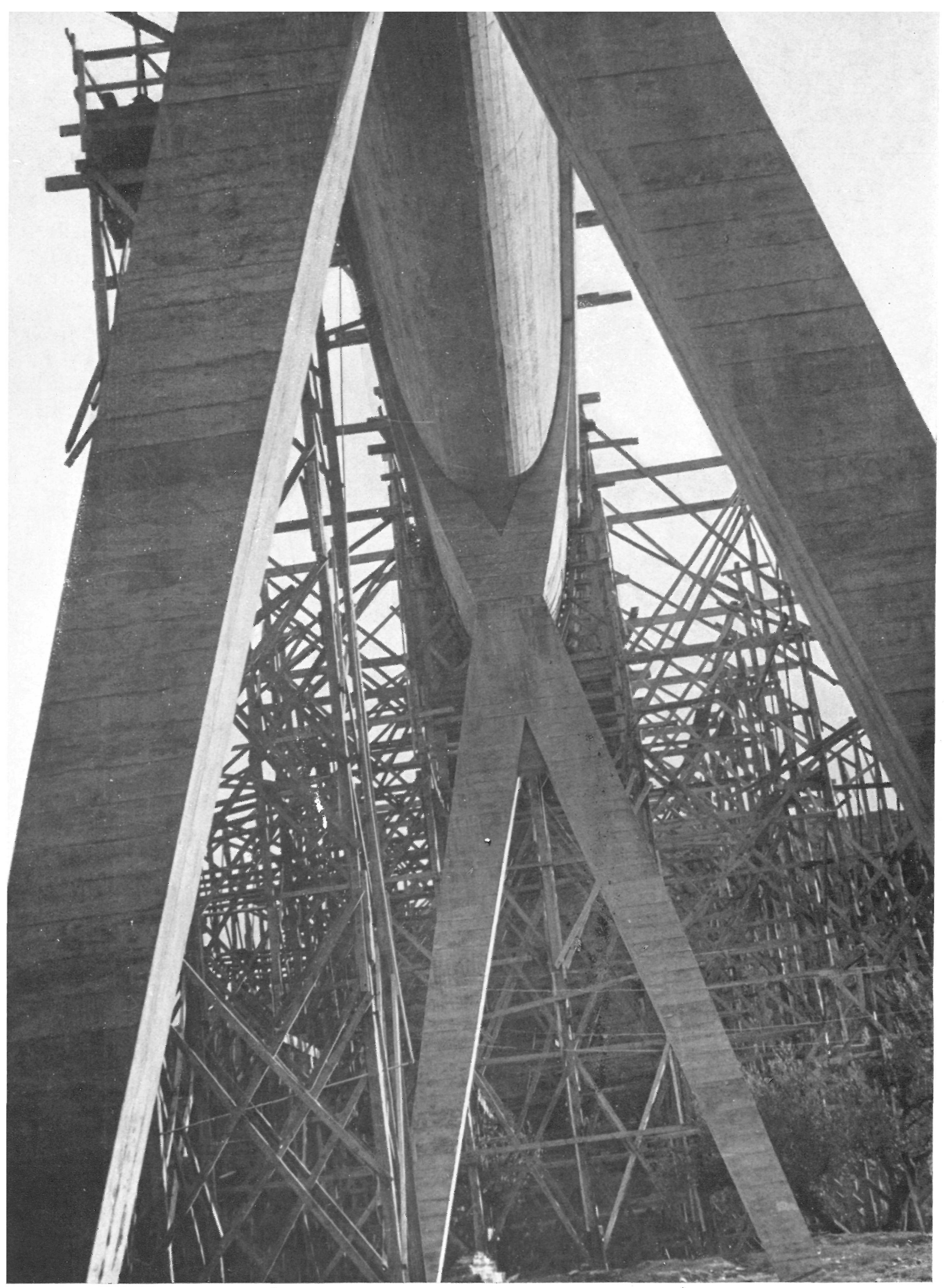

Vigas y ménsulas trabajan como una lámina cilíndrica entre los arcos de apoyo. Para la sección se eligió una curvatura en parábola de tercer grado, que da una buena sección hidráulica y, al mismo tiempo, una forma resistente aceptable.

Entre los varios acueductos construídos de este tipo, representan una longitud total de 450 metros. En ninguno de ellos ha aparecido fisuración ni fugas a través del hormigón, y todas las operaciones se hisieron fácil y económicamente. 